\title{
Multiple myeloma and oat cell carcinoma
}

\author{
A. G. SMITH AND R. L. C. CUMMING \\ From the Department of Haematology, Stobhill Hospital, Glasgow, UK
}

SUMMARY An association linking multiple myeloma with a higher incidence of carcinomatous tumours has been reported. The following case report describes a man diagnosed as having bronchogenic carcinoma found also to have myelomatosis. Aspects of this association are discussed.

\section{Case report}

A 60-year-old retired lorry driver had been attending the hospital hypertension clinic since 1971. Initially, control of his hypertension had been poor; in May 1973 he sustained a cardiovascular accident resulting in a minimal left hemiparesis. After this he remained well with no further complications.

In December 1974, a routine chest $x$-ray revealed bilateral hilar node enlargement, a right lower lobe opacity, and presumed pulmonary metastatic deposits. In view of the man's poor health and extensive disease, no further active investigations or treatment were contemplated at this stage.

In August 1975, his clinical state had deteriorated. The chest lesions had enlarged and he had become anaemic (Hb 9.1 g/dl). The ESR was over $150 \mathrm{~mm} / 1 \mathrm{st}$ hour and extensive rouleaux formation was noted on the blood film. The serum albumin was $30 \mathrm{~g} / \mathrm{l}$ and the total globulin was raised at $70 \mathrm{~g} / 1$. Electrophoresis revealed a dense band of gamma-globulin. He was admitted for further investigation with this new evidence of possible myelomatosis. In retrospect, a biochemistry report one year previously had shown a slightly raised globulin at $41 \mathrm{~g} / \mathrm{l}$.

Further investigation revealed Bence-Jones proteinuria. Sternal marrow aspiration confirmed myelomatosis (Figure). Immunoglobulin assays demonstrated an IgA myeloma (730 IU/1). In addition to the radiological chest findings, osteolytic lesions, consistent with either disease, were noted in the skull. Exfoliative cytology was suggestive of an oat cell carcinoma.

With confirmation of myelomatosis, it was considered justifiable to initiate chemotherapy. He was treated with melphalan and prednisolone. There was an initial clinical improvement not supported by

Received for publication 31 March 1977 laboratory evidence. In October 1975, he contracted a fatal bronchopneumonia.

At necropsy the gross appearances were those of carcinomatosis. Histologically the appearances of the pulmonary lesion and hilar nodes were those of an oat cell carcinoma. The skull deposits were confirmed as myeloma; also several small deposits on the surface of the right kidney showed identical histology.

\section{Discussion}

The occurrence of a bone marrow reactive plasmacytosis in relation to various disease states has been established (Fadem, 1952) and poses the problem whether it represents a variant of immune response or early myeloma. Apart from carcinoma, plasmacytosis is noted in a wide variety of diseases including lymphoproliferative disorders, chronic tuberculosis, and collagen diseases.

Monoclonal abnormalities of the gamma-globulins have been reported in these diseases. Takatsuki (1968) has published a comprehensive review on the occurrence of $M$-proteins in malignant and nonmalignant diseases, concluding that monoclonal plasma cell proliferation has a great diversity in its pathogenesis. The rise in M-protein is not always reflected by an increase in marrow plasma cells. Clear evidence suggesting an association between carcinoma and myeloma is found in one survey quoting a $19.3 \%$ incidence of carcinoma co-existent with myelomatosis (Weitzel, 1958). Corresponding figures for carcinoma with lymphoma, and carcinoma with carcinoma, were $8 \%$ and $4.2 \%$ respectively. Subsequent reports have supported these findings and have been more recently reviewed (Anderson and Vye, 1967). These authors also reported a malignant thymoma occurring in conjunction with myelomatosis. 


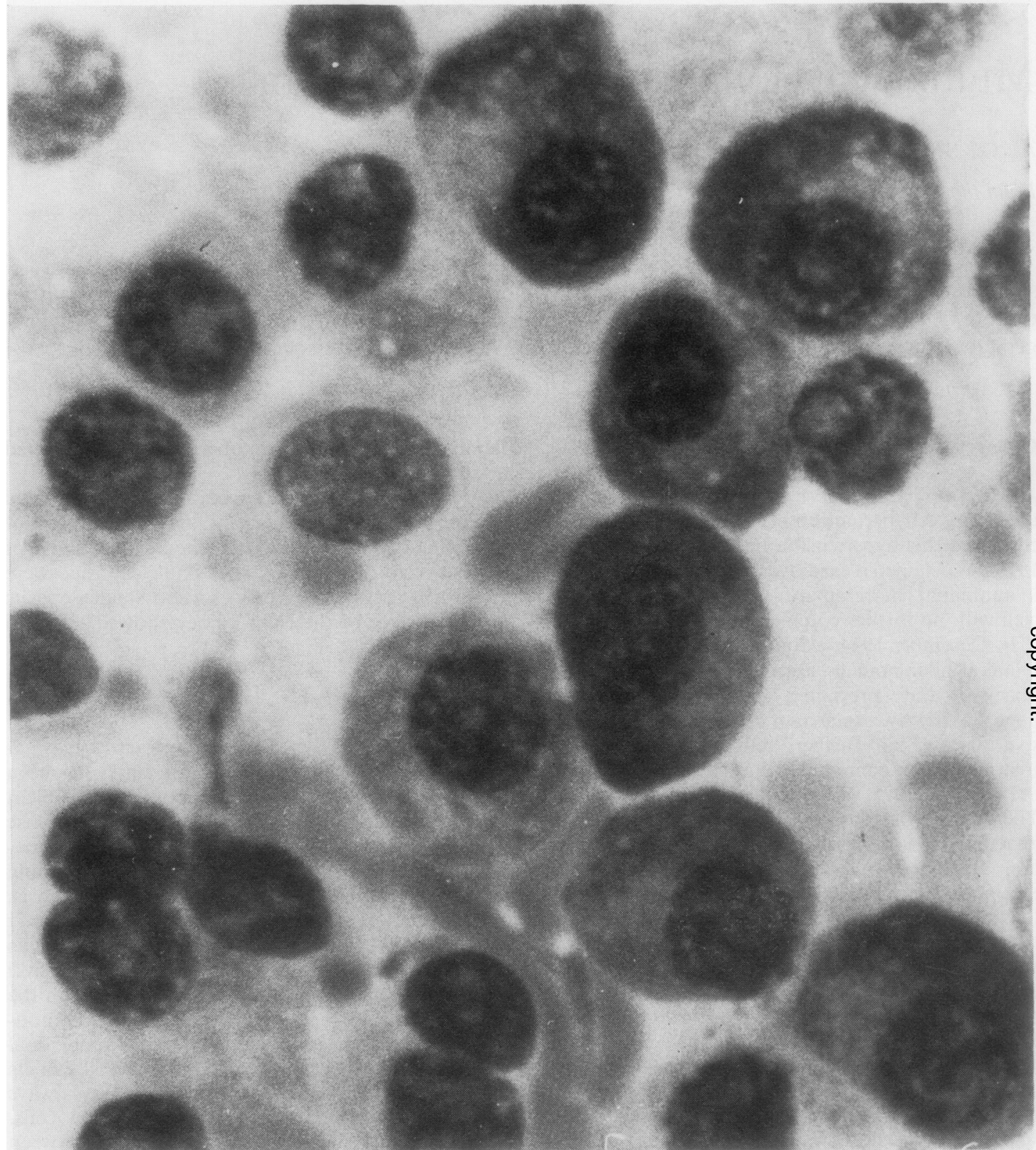

Figure Photomicrograph from bone marrow aspiration showing the marked plasma cell infiltration of myelomatosis. May-Grünwald-Giemsa stain. $\times 4580$.

The diversity of the immune reaction to chronic disease could account for the reports of plasmacytosis and M-proteins with a progression to myeloma in a small number. Equally, it must be considered that the apparent association of carcinoma with myelomatous disease may reflect impaired immuno- logical surveillance from the developing myeloma; current hypotheses on the growth of such tumours hold that myeloma can develop subclinically for up to 16 years if the growth is exponential, or five years if Gompertzian patterns are followed (Salmon, 1971). In conclusion, it must also be accepted that 
coincidence can account for the apparent association. Hobbs (1974) has pointed out that in the age group $50-60$ years a $2 \%$ incidence of paraproteins can be expected. In a large series of cancer patients, he has found a similar incidence of paraproteins.

\section{References}

Anderson, E. T., and Vye, M. V. (1967). Dysproteinemia of the myeloma type associated with a thymoma. Annals of Internal Medicine, 66, 141-149.

Fadem, R. S. (1952). Differentiation of plasmacytic responses from myelomatous diseases on the basis of bone-marrow findings. Cancer (Philad.), 5, 128-137.
Hobbs, J. R. (1974). The immunoglobulins and their disorders. In Blood and its Disorders, edited by R. M. Hardisty, and D. J. Weatherall, pp. 1319-1373. Blackwell, Oxford.

Salmon, S. E. (1971). Immunoglobulin synthesis and tumour cell number and the natural history of multiple myeloma. British Medical Journal, 2, 321.

Takatsuki, K. (1968). Plasma cell myeloma and related diseases in Japan; clinical and immunochemical studies on M-components. Acta Haematologica Japonica, 31, 636-663.

Weitzel, R. A. (1958). Carcinoma coexistent with malignant disorders of plasma cells. Cancer (Philad.), 11, 546-549. 